\title{
Undercut Formation Mechanism in Keyhole Plasma Arc Welding
}

\author{
$X$-ray transmission, high-speed video camera, and thermal camera \\ systems were developed to study undercut formation
}

BY A. V. NGUYEN, D. WU, S. TASHIRO, AND M. TANAKA

\begin{abstract}
Undercut formation is a common weld defect in keyhole plasma arc welding. Based on the comprehensive experimental measurement of the weld pool convection with the help of $x$-ray transmission, high-speed video camera, and thermal camera systems, undercut formation is suggested to be caused by the irregular fluid flow and uneven energy distribution of the weld pool. As the plasma gas rate is increased, the counterclockwise eddy inside the weld pool is increased, and the backward flow at the top surface is decreased, so more energy is transported to the bottom surface, while less energy is transported to the top surface. The rear part of the top weld pool is easily solidified, so a teardrop-shaped profile is easily formed. Due to the strong inward flow at the top surface caused by the teardrop-shaped top weld pool profile and the dominant counterclockwise eddy inside the weld pool, more energy is transported from the lateral sides to the centerline of the top weld pool. A high-temperature zone is formed at the centerline of the top weld pool, while the lateral sides are easily prematurely solidified, causing the undercut formation at the top surface.
\end{abstract}

\section{KEYWORDS}

- Keyhole Plasma Arc Welding • Undercut Formation

-X-Ray Transmission System • Thermal Camera

\section{Introduction}

Keyhole plasma arc welding (KPAW) has a promising future in the welding of automobiles (Ref. 1), airplanes (Ref. 2), rockets (Ref. 3), and structural steels (Ref. 4) due to its high-energy density, low equipment cost, and joint tolerance. However, welding defects (Ref. 5), such as undercut, are easily formed during welding, which decrease the static, fatigue, and fracture strength of the weld joint.

The undercut formation mechanism had been widely discussed in arc welding based on experimental observation and numerical simulation. In the gas tungsten arc welding (GTAW) process, the inward Marangoni force caused by the positive surface tension temperature coefficient was proposed by Mills to explain the undercut formation (Ref. 6). However, the undercut was not generated during the GTAW of high-sulphur steel (positive surface tension temperature coefficient) with low welding speed. Mendez found that a thin layer of liquid metal was formed under the arc due to the large arc pressure in the high-current GTAW process. The premature solidification of this thin liquid layer initiated the undercut (Ref. 7). Meng developed a three-dimensional numerical model for the high-speed GTAW process (Refs. 8, 9). The premature solidification of the thin liquid layer at the periphery and the inward flow at the trailing periphery promoted the undercut formation (Ref. 8). He also proposed that the arc shear stress was the dominant driven force for the weld pool deformation and backward flow of the liquid metal (Ref. 9). However, the arc shear stress and arc pressure in his studies were calculated based on the empirical equations. In the submerged arc welding (SAW) process, based on the $\mathrm{x}$-ray observation, the undercut occurred when the liquid metal was displaced more than the solidification point (Ref. 10). The large arc pressure was suggested to be responsible for the undercut formation (Ref. 11). In the gas metal arc welding (GMAW) process, Nguyen suggested that the backward flow of the liquid metal caused by the arc pressure and droplet impact was the main reason for the undercut and humping formation (Ref. 12). Based on the observation of the weld pool and the movement of the tracer particles, Zong suggested that the large longitudinalto-transverse velocity ratio, and the inward flow in the middle of the weld pool, contributed to the undercut formation (Refs. 13, 14). It can be concluded from previous studies that the weld pool convection in arc welding plays an important role in the undercut formation.

It should be noted that the undercut formation in the KPAW process is different from that in the GTAW, SAW, and GMAW processes. Undercut is likely formed in the GTAW, SAW, and GMAW processes with high current and high welding speed (Refs. 8, 10,12), while it can be formed in the KPAW process with low current and low welding speed. This may be caused by the formation of the penetrated keyhole and the complex weld pool convection. Previous studies of complete-joint-penetration laser welding showed the molten 

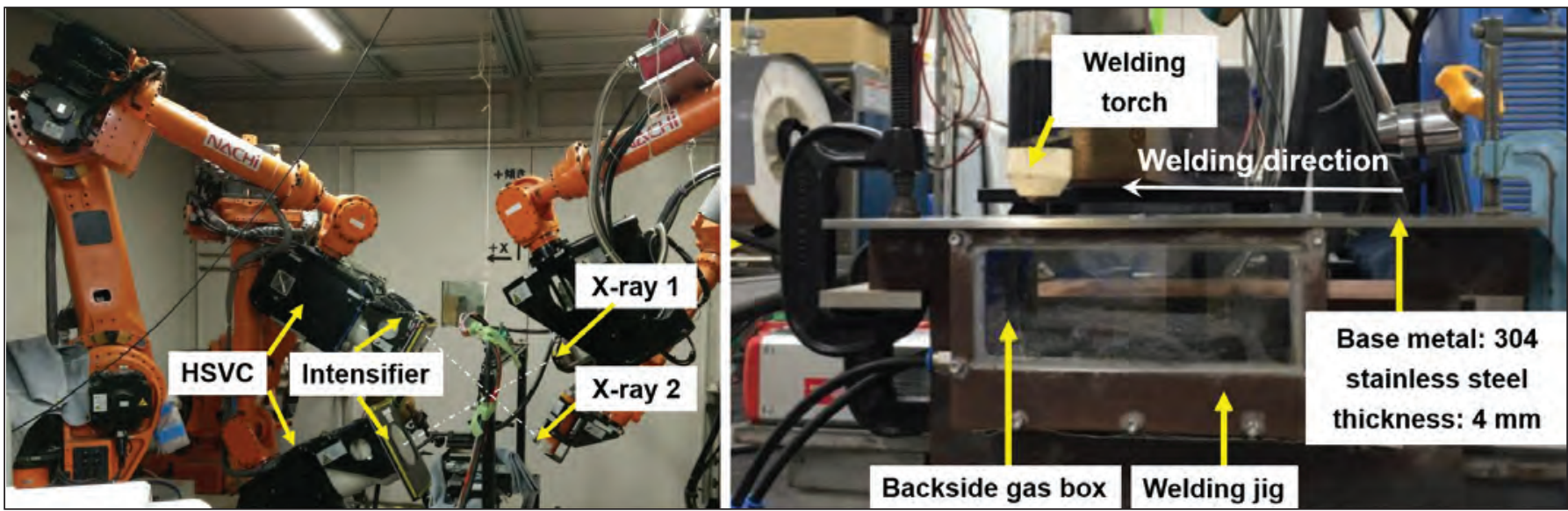

Fig. 1-Photographs of the X-ray transmission system and welding equipment.

metal was pressured toward the bottom surface, which caused redistribution of the thermal energy between the top and bottom welds (Ref. 15) and facilitated the formation of weld defects on the top and bottom surfaces (Ref. 16). Even though experimental observation and numerical simulation have been carried out to analyze the keyhole behavior (Ref. 17), keyhole stability (Refs. 18, 19), weld pool convection (Refs. 20-22), and weld defect formation (Ref. 5) in the KPAW process, the weld pool convection in previous numerical simulations is different from the experimental results (Ref. 23), and the undercut formation mechanism has not been revealed.

In this study, the convective patterns inside the weld pool in the KPAW process were measured by the $\mathrm{x}$-ray transmission system. The convective patterns on the weld pool surfaces were measured by tracing the movement of the zirconia particles based on the high-speed video camera system. The temperature of the weld pool surface was measured by the thermal camera system. Based on the comprehensive experiments, the fluid flow and the temperature distribution of the weld pool were analyzed. For the first time, the undercut formation mechanism in the KPAW process is revealed in detail.

\section{Experimental Procedures}

Figure 1 shows a photograph of the experimental setup. A transfer-type plasma arc welding torch (100WH, Nippon Steel Welding \& Engineering Co. Ltd.) and a welding power source (NW-300ASR, Nippon Steel Welding \& Engineering Co. Ltd.) were used in the experiments. The x-ray transmission system consisting of two sets of $\mathrm{x}$-ray power sources and image intensifiers as well as a high-speed video camera was used to observe the movement of 0.5 -mm-diameter tungsten particles, thus allowing the convective patterns inside the weld pool to be measured. The $\mathrm{x}$-ray 1 power source with the tube current of $1.0 \mathrm{~mA}$ and the tube voltage of $230.0 \mathrm{kV}$ was located at the upper side of the base metal. The x-ray 2 power source with the tube current of $3.5 \mathrm{~mA}$ and the tube voltage of $225.0 \mathrm{kV}$ was located at the lower side of the base metal. The image intensifiers were used to convert the $\mathrm{x}$-ray transmission images to visible images,

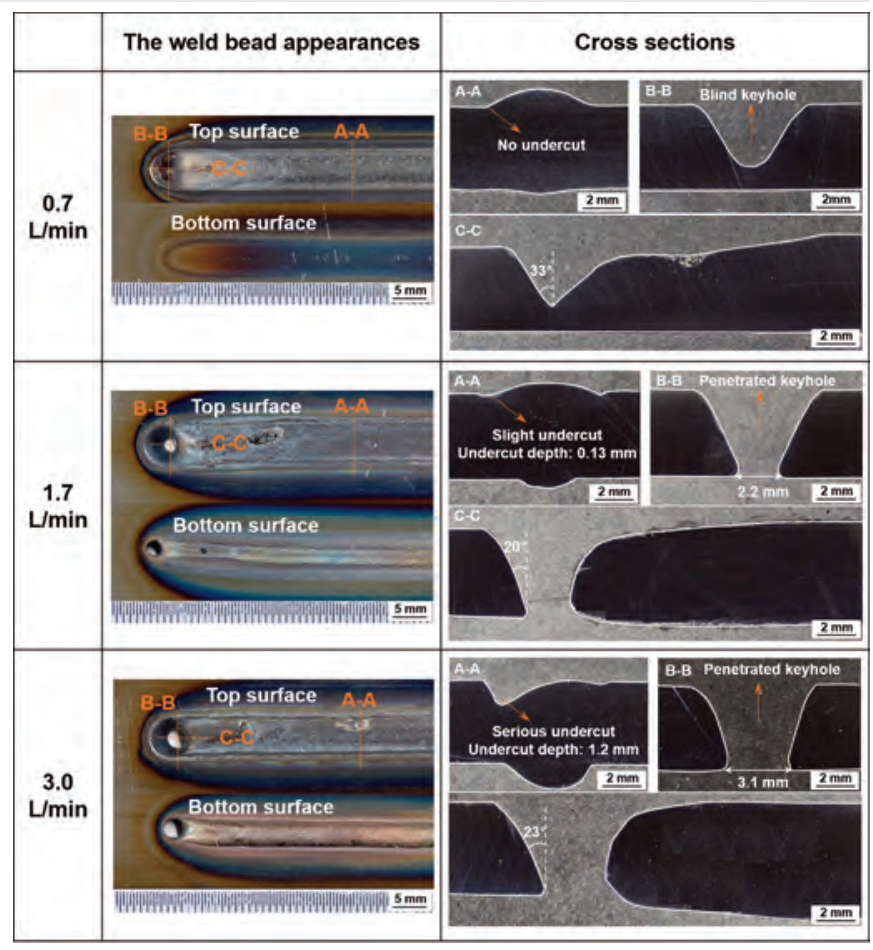

Fig. 2 - Weld bead appearances and cross sections of the weld beads.

which were then captured by the high-speed video camera with the frame rate of 1000 frames/s. During welding, the movement of zirconia particles on the top and bottom weld pool surfaces were measured by another high-speed video camera with the frame rate of 3000 frames/s, thus allowing the convective patterns on the weld pool surfaces to be measured. It should be noted that the tungsten particles or the zirconia particles were put into the prefabricated holes in the base metal.

The thermal camera (Miro Ex4 Phantom, Vision Research Inc.), including three color sensors composed of red (R), green (G), and blue (B), was used to take the weld pool surfaces images with the frame rate of 2000 frames/s. It should be noted that to avoid the strong radiation of the arc, the weld pool surface images were taken immediately after 
A

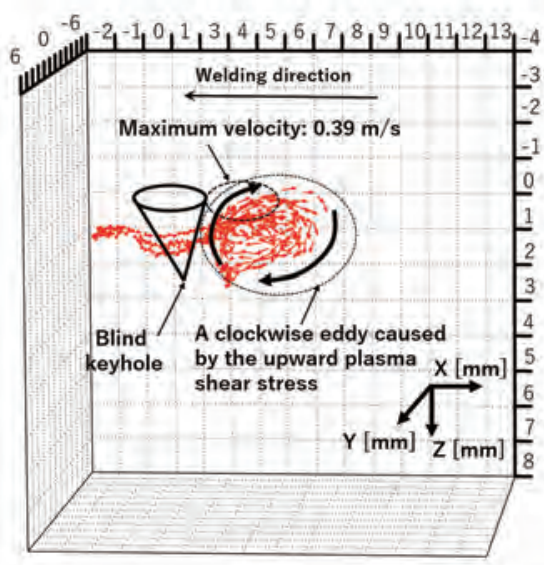

B

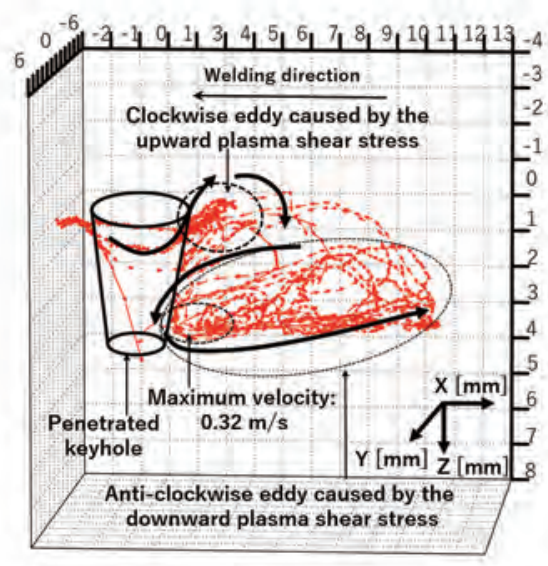

C

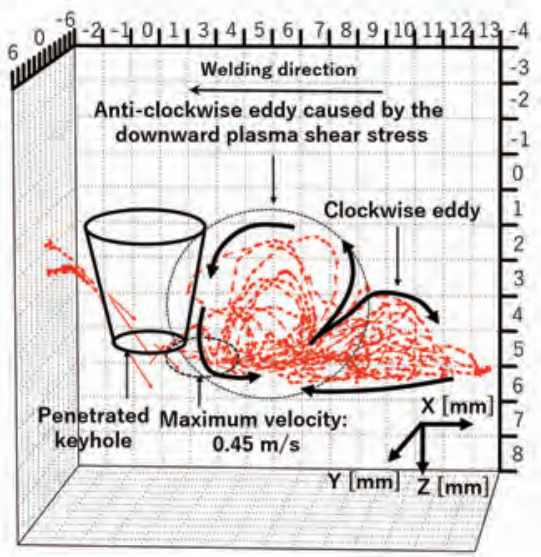

Fig. 3 - The three-dimensional convective patterns inside the weld pool: $A-0.7 \mathrm{~L} / \mathrm{min} ; \mathrm{B}-1.7 \mathrm{~L} / \mathrm{min} ; \mathrm{C}-3.0 \mathrm{~L} / \mathrm{min}$.
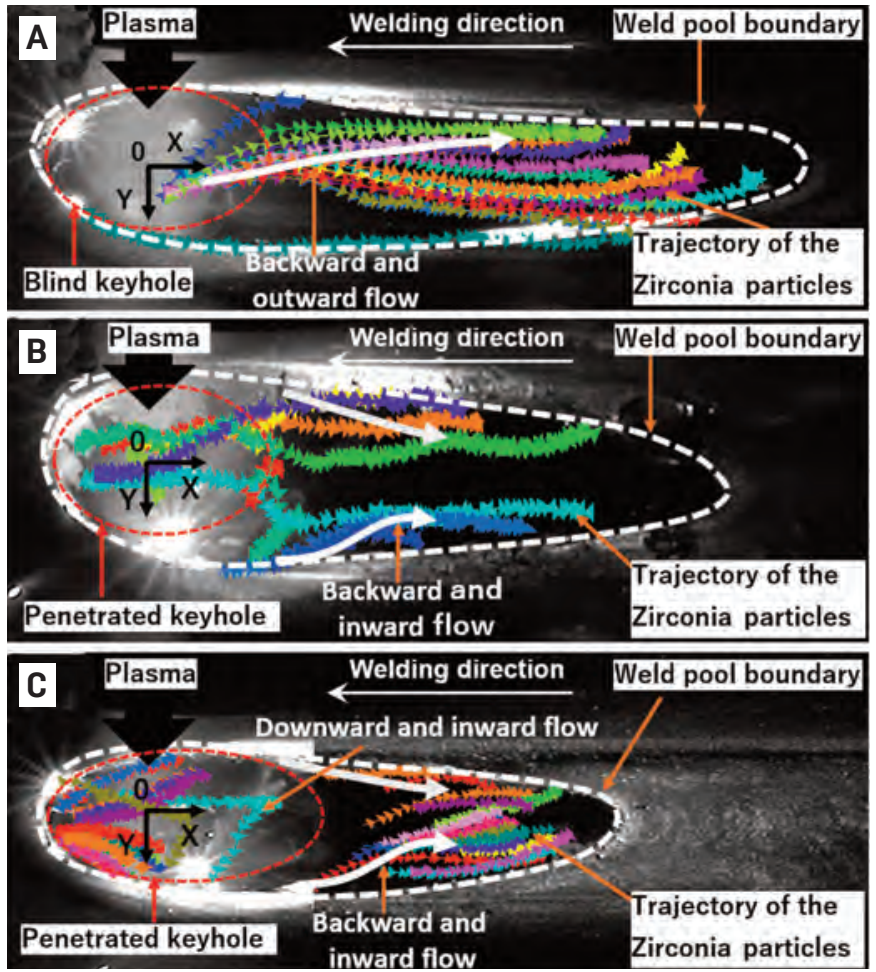

Fig. 4 - The convective pattern at the top surface of the weld pool: $A-0.7 \mathrm{~L} / \mathrm{min} ; \mathrm{B}-1.7 \mathrm{~L} / \mathrm{min} ; \mathrm{C}-3.0 \mathrm{~L} / \mathrm{min}$.

switching off the main arc. The main arc completely disappeared within $1.0 \mathrm{~ms}$. In our previous study, it was found that the decrease of the surface temperature was negligible within 2 ms after cutting the arc (Ref. 24). The weld pool temperature was calculated from the ratio of the $\mathrm{R}$ sensor signal to the G sensor signal in the image based on the twocolor pyrometry method. Detailed descriptions of the experimental methods can be seen in our previous work (Ref. 23).

The stainless steel SUS304 plates with the dimensions of $300 \times 100 \times 4 \mathrm{~mm}$ were used as the base metal in the experiments. The torch orifice diameter was $2.0 \mathrm{~mm}$, and the electrode setback was $3 \mathrm{~mm}$. The distance between the nozzle and the base metal was $5 \mathrm{~mm}$. The welding current was direct current $120 \mathrm{~A}$, and the welding voltage was approximately $27 \mathrm{~V}$. The welding speed was $3 \mathrm{~mm} / \mathrm{s}$. Pure argon (Ar) was used as the main plasma gas and the shielding gas. During welding, the backshielding gas was introduced to a backside gas box, which was put on the welding jig, avoiding oxidation of the back weld bead. The main plasma gas flow rate was $0.7,1.7$, and $3.0 \mathrm{~L} / \mathrm{min}$. The shielding gas flow rate was $7.5 \mathrm{~L} / \mathrm{min}$.

\section{Results}

\section{Influence of Plasma Gas Rate on Weld Bead Formation}

The weld bead appearances and the cross sections of the weld beads in cases of $0.7,1.7$, and $3.0 \mathrm{~L} / \mathrm{min}$ are indicated in Fig. 2. In the case of $0.7 \mathrm{~L} / \mathrm{min}$, only a blind keyhole was formed, and no undercut was generated. The inclination of the front keyhole wall about $33 \mathrm{deg}$.

In the case of $1.7 \mathrm{~L} / \mathrm{min}$, a penetrated keyhole was formed, and the slight undercut was generated at the weld toe. The undercut depth was about $0.13 \mathrm{~mm}$. The keyhole width at the bottom surface at the B-B cross section was about 2.2 $\mathrm{mm}$. The inclination of the front keyhole wall was about 20 deg.

In the case of $3.0 \mathrm{~L} / \mathrm{min}$, serious undercut was generated at the weld toe. The undercut depth was about $1.2 \mathrm{~mm}$. The keyhole width at the bottom surface at the B-B cross section was about $3.1 \mathrm{~mm}$. The inclination of the front keyhole wall was about 23 deg.

\section{The Influence of Plasma Gas Rate on the Fluid Flow}

The three-dimensional convective patterns inside the weld pool in cases of $0.7,1.7$, and $3.0 \mathrm{~L} / \mathrm{min}$ are indicated in Fig. 3. In the case of $0.7 \mathrm{~L} / \mathrm{min}$, only a blind keyhole was formed. The molten metal flowed upward and backward along the rear keyhole wall. Therefore, only a clockwise eddy was formed inside the weld pool. The maximum velocity $(0.39 \mathrm{~m} / \mathrm{s})$ was located at the convective pattern near the top surface.

In the case of $1.7 \mathrm{~L} / \mathrm{min}$, a clockwise eddy was formed in- 

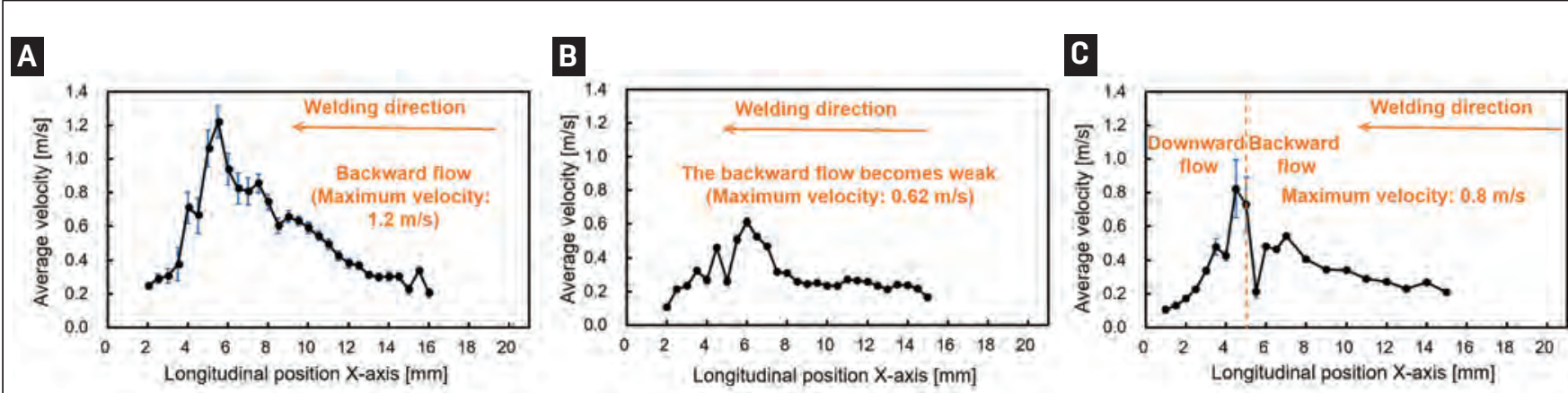

Fig. 5 - The distribution of average flow velocity at the top surface of the weld pool: $A-0.7 \mathrm{~L} / \mathrm{min} ; B-1.7 \mathrm{~L} / \mathrm{min} ; \mathrm{C}-3.0 \mathrm{~L} / \mathrm{min}$.

side the top weld pool, and a counterclockwise eddy was formed inside the bottom weld pool. The maximum velocity $(0.32 \mathrm{~m} / \mathrm{s})$ was located at the convective pattern near the bottom surface.

In the case of $3.0 \mathrm{~L} / \mathrm{min}$, near the rear keyhole wall, only a counterclockwise eddy can be seen inside the weld pool. At the rear part of the bottom weld pool, a clockwise eddy was formed. The maximum velocity $(0.45 \mathrm{~m} / \mathrm{s})$ was located at the convective pattern near the bottom surface.

It can be concluded from Fig. 3 that as the plasma gas rate was increased, the counterclockwise eddy inside the top weld pool became smaller, and then disappeared.

The convective patterns at the top surface of the weld pool in cases of 0.7, 1.7, and $3.0 \mathrm{~L} / \mathrm{min}$ are presented in Fig. 4. In the case of $0.7 \mathrm{~L} / \mathrm{min}$, all the zirconia particles flowed backward and outward to the rear part of the top weld pool.

In the case of $1.7 \mathrm{~L} / \mathrm{min}$, the zirconia particles flowed backward to the rear part of the top weld pool. However, at the lateral sides of the top weld pool, the particles reached the top weld pool periphery, and then flowed inward.

In the case of $3.0 \mathrm{~L} / \mathrm{min}$, near the keyhole, the zirconia particles flowed downward. At the middle of the top weld pool, the zirconia particles flowed backward and inward.

The distribution of the average flow velocity at the top surface of the weld pool in cases of $0.7,1.7$, and $3.0 \mathrm{~L} / \mathrm{min}$ are presented in Fig. 5 . In the case of $0.7 \mathrm{~L} / \mathrm{min}$, from the front part to the rear part of the top weld pool, the flow velocity was first increased and then decreased. The maximum velocity (about $1.2 \mathrm{~m} / \mathrm{s}$ ) was located at the middle of the top weld pool.

In the case of $1.7 \mathrm{~L} / \mathrm{min}$, the flow velocity tendency was similar to that in the case of $0.7 \mathrm{~L} / \mathrm{min}$. The maximum velocity (about $0.62 \mathrm{~m} / \mathrm{s}$ ) was also located at the middle of the top weld pool.

In the case of $3.0 \mathrm{~L} / \mathrm{min}$, the maximum velocity (about $0.8 \mathrm{~m} / \mathrm{s}$ ) was found near the top keyhole, in which the zirconia particles flowed downward and inward.

It can be concluded from Figs. 4 and 5 that when a penetrated keyhole is formed, at the top surface, the inward flow can be observed at the middle of the top weld pool, and the backward flow becomes weak. If the plasma gas rate is too large, the downward and inward flow with high velocity can be observed near the top keyhole.

The convective patterns at the bottom surface of the weld pool in cases of 1.7 and $3.0 \mathrm{~L} / \mathrm{min}$ are presented in Fig.

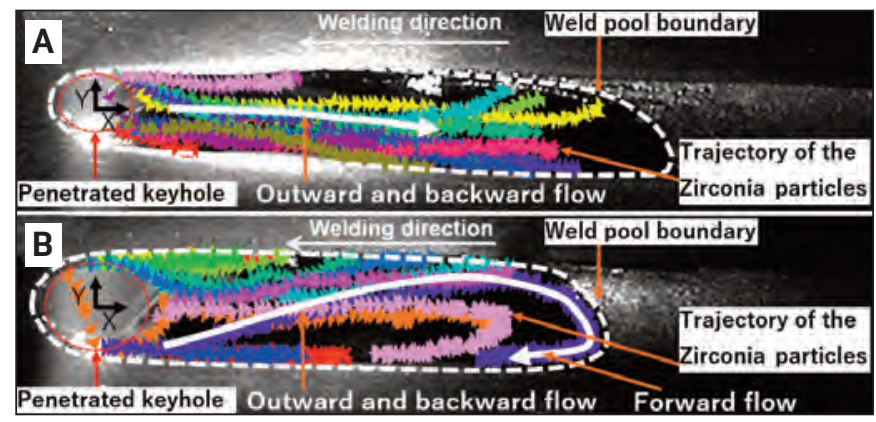

Fig. 6 - The convective pattern at the bottom surface of the weld pool: $A-1.7 \mathrm{~L} / \mathrm{min} ; \mathrm{B}-3.0 \mathrm{~L} / \mathrm{min}$.

6. In the case of $1.7 \mathrm{~L} / \mathrm{min}$, the zirconia particles flowed outward and backward to the rear part of the bottom weld pool. There were two convective patterns in the case of $3.0 \mathrm{~L} / \mathrm{min}$. All the particles flowed backward from the keyhole toward the rear part of the bottom weld pool. At the rear part of the bottom weld pool, several particles flowed forward.

The distribution of the average flow velocity at the bottom surface of the weld pool in cases of 1.7 and $3.0 \mathrm{~L} / \mathrm{min}$ are presented in Fig. 7. It can be seen that from the keyhole to the rear part of the weld pool, the flow velocity was decreased. The maximum flow velocity just behind the keyhole in the case of $3.0 \mathrm{~L} / \mathrm{min}$ (about $1.3 \mathrm{~m} / \mathrm{s}$ ) was higher than that in the case of $1.7 \mathrm{~L} / \mathrm{min}$ (about $1.15 \mathrm{~m} / \mathrm{s}$ ).

\section{The Influence of Plasma Gas Rate on Temperature Distribution}

The top weld pool and temperature distribution in the cases of $0.7,1.7$, and $3.0 \mathrm{~L} / \mathrm{min}$ are presented in Fig. 8. In the case of $0.7 \mathrm{~L} / \mathrm{min}$, the top weld pool was elliptical, and there were two high-temperature zones located at the lateral sides of the top weld pool ( $\mathrm{X}=4 \sim 5 \mathrm{~mm}$ ). The premature solidification of the molten metal at the lateral sides can't be seen. From the front to the rear part of the top weld pool, the temperature was first increased and then decreased.

In the case of $1.7 \mathrm{~L} / \mathrm{min}$, the top weld pool length was decreased. The high-temperature zone was located at the centerline of the top weld pool ( $\mathrm{X}=5 \mathrm{~mm}$ ). The maximum temperature was about $1870 \mathrm{~K}$. The premature solidification of the molten metal can be seen at the lateral sides.

In the case of $3.0 \mathrm{~L} / \mathrm{min}$, the top weld pool length was the 


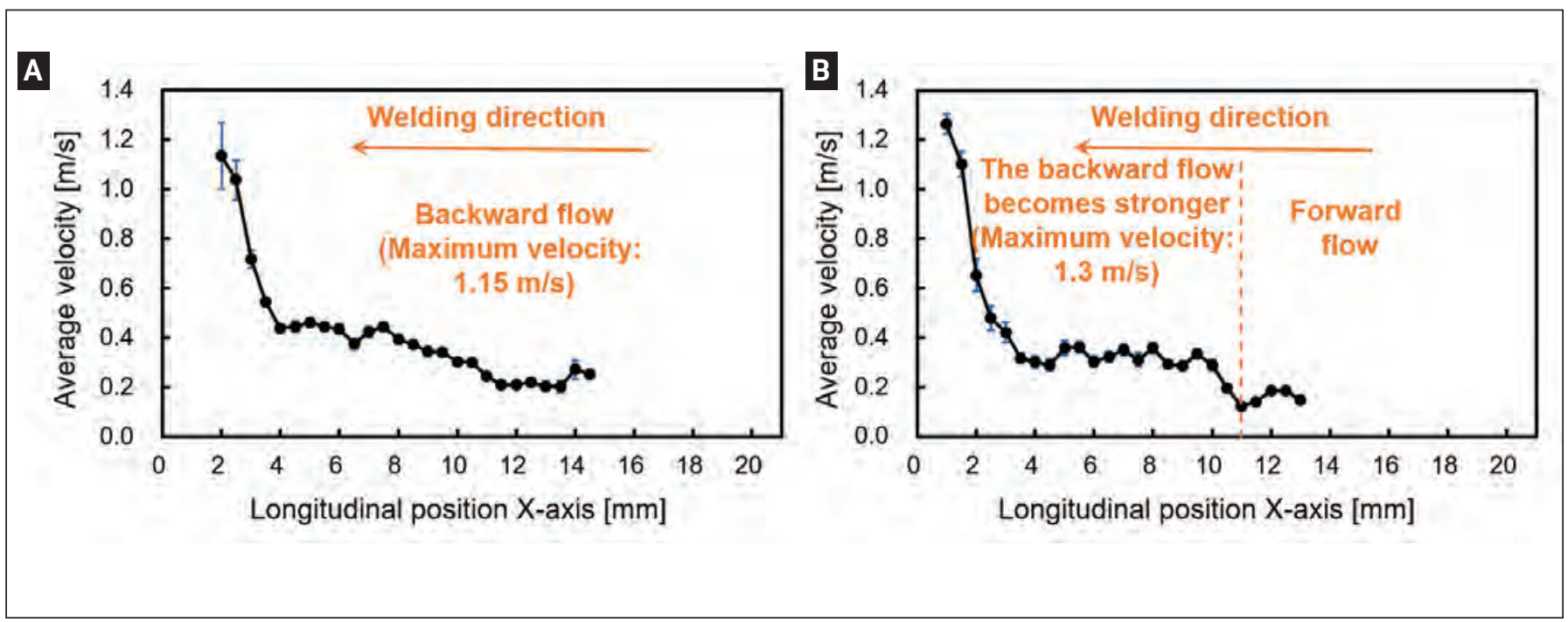

Fig. 7 - The distribution of the average flow velocity at the bottom surface of the weld pool: $A-1.7 \mathrm{~L} / \mathrm{min} ; B-3.0 \mathrm{~L} / \mathrm{min}$.

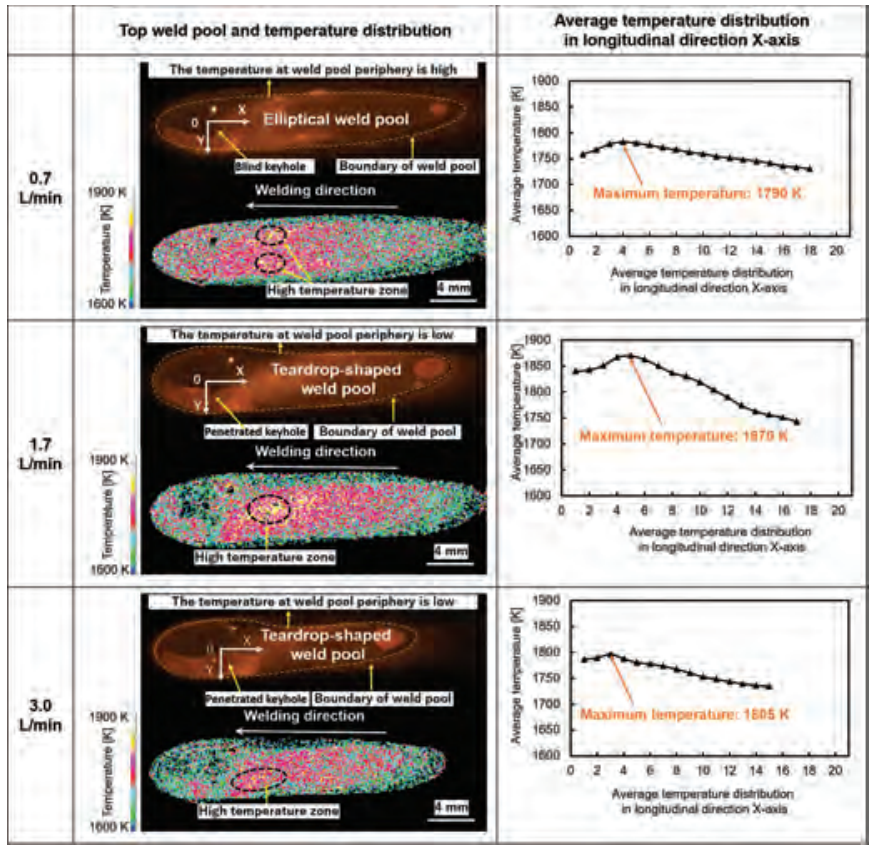

Fig. 8 - The top weld pool and temperature distribution.

smallest. The high-temperature zone was also located at the centerline of the top weld pool $(\mathrm{X}=3.5 \mathrm{~mm})$. The maximum temperature was about $1805 \mathrm{~K}$. The premature solidification of the molten metal can be seen at the lateral sides.

The bottom weld pool and temperature distribution in cases of 1.7 and $3.0 \mathrm{~L} / \mathrm{min}$ are presented in Fig. 9. The bottom weld pool was much longer and wider in the case of 3.0 $\mathrm{L} / \mathrm{min}$. The bottom weld pool length was about $17 \mathrm{~mm}$ in the case of $3.0 \mathrm{~L} / \mathrm{min}$ and $14 \mathrm{~mm}$ in the case of $1.7 \mathrm{~L} / \mathrm{min}$. The temperature distributions in both cases have the same tendency with the highest value located just behind the keyhole. However, the maximum temperature was higher in the case of $1.7 \mathrm{~L} / \mathrm{min}$, where $1859 \mathrm{~K}$ at $\mathrm{X}=1 \mathrm{~mm}$ in comparison to the case of $3.0 \mathrm{~L} / \mathrm{min}$ where $1830 \mathrm{~K}$ at $\mathrm{X}=1 \mathrm{~mm}$.

It can be concluded from Figs. 8 and 9 that as the plasma gas rate was increased, the weld pool length was decreased at the top surface, but increased at the bottom surface. The high-temperature zone moved from the lateral sides to the centerline of the top weld pool.

\section{Discussion}

In this study, an electrode-arc model was developed to study the plasma arc physics in the KPAW process. The detailed description of the numerical model can be seen in our previous work (Ref. 25). The influence of the plasma gas rate on the weld pool convection and weld bead formation was analyzed, and the undercut formation mechanism was revealed.

\section{The Relationship between Plasma Gas Rate and Weld Pool Convection, Weld Bead Formation}

Figure 10 shows the distribution of the arc pressure $(\mathrm{Pa})$ and plasma shear stress $(\tau)$ of a flat surface with different plasma gas rates. When the plasma gas rate was $0.7 \mathrm{~L} / \mathrm{min}$, the maximum arc pressure was about $1562 \mathrm{~Pa}$, and the maximum plasma shear stress was about $330 \mathrm{~Pa}$. The arc pressure and plasma shear stress were so small that only a blind keyhole was formed.

It should be noted that in the blind keyhole case, the arc pressure was downward, and the plasma shear stress caused by the reverse flow of the arc plasma was upward and backward (Ref. 21). Based on Figs. 3A and 4A, it can be concluded that the plasma shear stress was the dominant driven force for the clockwise eddy inside the weld pool and the backward and outward flow on the top surface. The arc pressure had minor influence on the weld pool convection.

The Peclet number of the weld pool in the blind keyhole case is calculated by Equation 1, and its value is about 202. The Peclet number is a dimensionless number showing the ratio between convection and conduction. The much higher Peclet number in the blind keyhole case means the heat transportation by the fluid flow is the dominant mechanism for the energy transportation inside the weld pool (Ref. 26). 


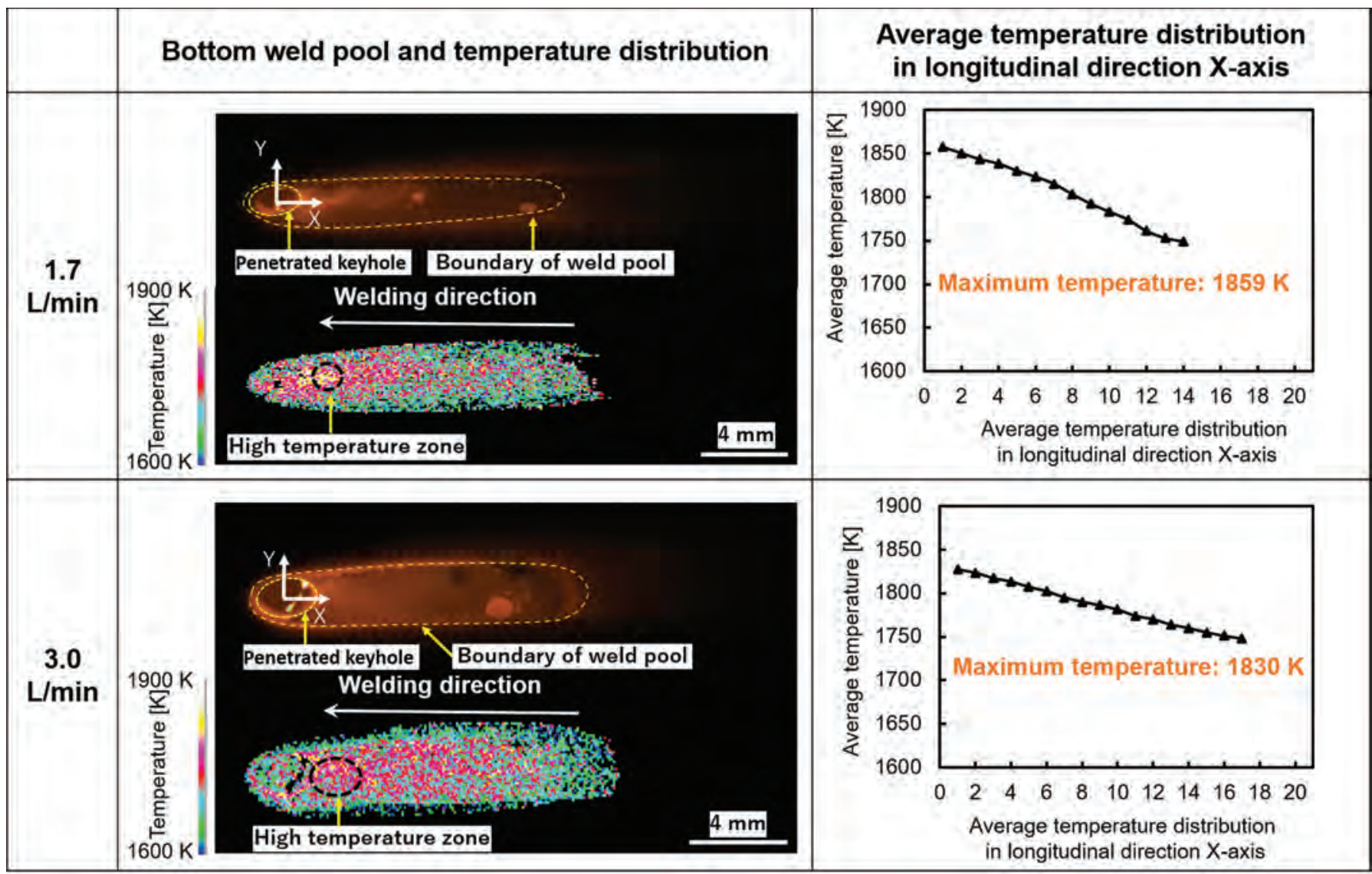

Fig. 9 - The bottom weld pool and temperature distribution.

$$
P e=\rho C V L / K
$$

where $\rho$ is the fluid density $\left(6900 \mathrm{~kg} / \mathrm{m}^{3}\right), C$ is the specific heat $(720 \mathrm{~J} / \mathrm{kg} \cdot \mathrm{K}), L$ is the characteristic length (weld pool radius: $0.00296 \mathrm{~m}), V$ is the characteristic velocity $(0.39$ $\mathrm{m} / \mathrm{s})$, and $K$ is the thermal conductivity $(28.4 \mathrm{~W} / \mathrm{m} \cdot \mathrm{K})$.

Based on Figs. 4A and 8, the schematic diagram of the weld pool at the top view in the case of $0.7 \mathrm{~L} / \mathrm{min}$ can be obtained. As shown in Fig. 11, the molten metal at the top surface flowed outward and backward due to the plasma shear stress, so a lot of energy was transported to the weld pool periphery and rear. An elliptical weld pool was formed. The temperature of the molten metal at the middle of the weld pool was high, and two high-temperature zones were located at the lateral sides of the weld pool. The premature solidification of the weld pool periphery at the maximum width of the weld pool did not occur, so the undercut was not formed in the blind keyhole case.

As shown in Fig. 10, when the plasma gas rate was 1.7 $\mathrm{L} / \mathrm{min}$, the maximum arc pressure was about $4532 \mathrm{~Pa}$, and the maximum plasma shear stress was about $630 \mathrm{~Pa}$. The arc pressure and plasma shear stress were so large that a penetrated keyhole was formed. As shown in Fig. 12, at the top surface of the weld pool, the plasma shear stress was upward and backward due to the reverse flow of the arc plasma (Ref. 27), so a clockwise eddy was formed inside the top weld pool. At the bottom surface of the weld pool, the plasma shear stress was downward and backward due to the downward flow of the arc plasma. Besides, the arc pressure was downward, so a counterclockwise eddy was formed inside the bottom weld pool. The downward flow of the arc plasma (the downward plasma shear stress) was strong, while the reverse flow (the upward plasma shear stress) was relatively low, so the size of the bottom eddy was larger than that of the top eddy, as shown in Fig. 3B. The maximum backward flow velocity (about $0.62 \mathrm{~m} / \mathrm{s}$ ) at the top surface was much smaller than that at the bottom surface (about $1.15 \mathrm{~m} / \mathrm{s}$ ), and was also much smaller than that of the $0.7 \mathrm{~L} / \mathrm{min}$ case (about $1.2 \mathrm{~m} / \mathrm{s}$ ). More energy was transported to the bottom surface, and less energy was transported to the top surface, so the weld pool length at the top surface was smaller than that of the $0.7 \mathrm{~L} / \mathrm{min}$ case.

It is obvious that the inward flow can be observed at the top surface at the middle of the top weld pool in the case of $1.7 \mathrm{~L} / \mathrm{min}$. This inward flow was proposed to be responsible for the undercut formation in the high-speed and highcurrent GTAW (Ref. 8) and GMAW processes (Refs. 13, 14). Meng proposed that the inward flow was caused by the teardrop-shaped weld pool profile (Ref. 8). Zong suggested that the inward flow was dominated by the Marangoni force (Refs. 13, 14). However, it should be noted that in the KPAW process, the maximum temperature of the weld pool is less than $2000 \mathrm{~K}$, and the surface tension temperature coefficient of 304 stainless steel is negative, so the Marangoni force is outward. The inward flow in the KPAW process can be explained as follows.

Based on Figs. 4B and 8, the schematic diagram of the weld pool at the top view in the case of $1.7 \mathrm{~L} / \mathrm{min}$ can be ob- 


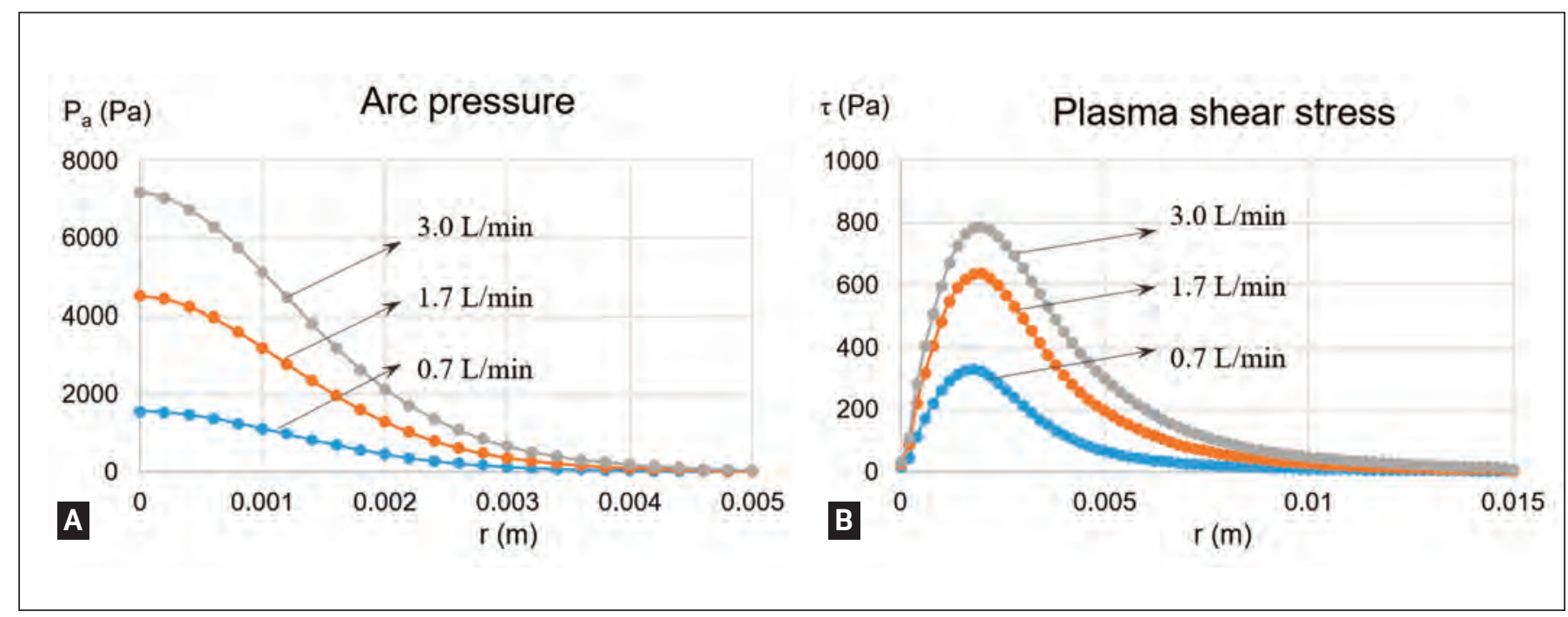

Fig. 10 - The distribution of arc pressure and plasma shear stress of a flat surface with different plasma gas rates.

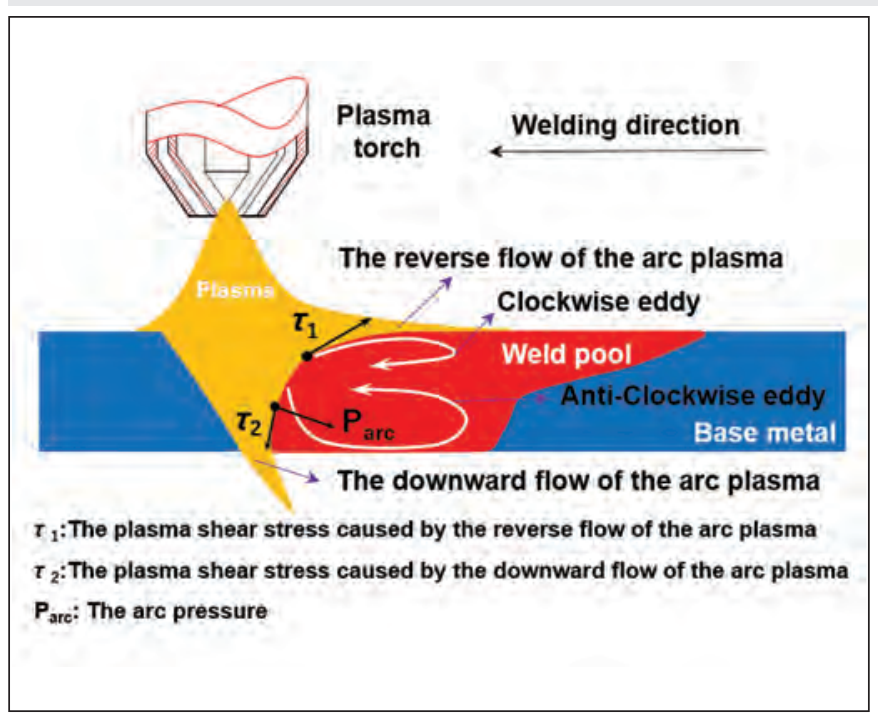

Fig. 11 - Schematic of the weld pool at the top view in the case of $0.7 \mathrm{~L} / \mathrm{min}$.

tained. As shown in Fig. 13, the upward plasma shear stress caused by the reverse flow of the arc plasma at the top surface was low, so the backward flow at the top surface was weak, and little energy could be transported to the rear part of the top weld pool. The rear part of the top weld pool was easily solidified, so a teardrop-shaped profile was formed. When the molten metal reached the solidified weld pool periphery, it changed the flow direction, resulting in the inward flow.

Due to the inward flow, more molten metal and energy were transported from the lateral sides to the centerline of the top weld pool, leading to the formation of the hightemperature zone at the centerline of the top weld pool. Without enough molten metal and energy, the lateral sides of the top weld pool were easily prematurely solidified, causing the undercut formation.

As shown in Fig. 10, when the plasma gas rate was 3.0 $\mathrm{L} / \mathrm{min}$, the maximum arc pressure was about $7179 \mathrm{~Pa}$, and the maximum plasma shear stress was about $787 \mathrm{~Pa}$. The arc pressure and plasma shear stress were very large, so a large penetrated keyhole was formed. The reverse flow of the arc plasma at the top surface (the upward plasma shear stress) was very weak, and the downward flow of the arc plasma (the downward plasma shear stress) was very strong, so near the rear keyhole wall, only a counterclockwise eddy was formed inside the weld pool, and the molten metal flowed downward and inward with high velocity at the top surface (maximum velocity: about $0.8 \mathrm{~m} / \mathrm{s}$ ). The maximum backward flow velocity at the top surface (about $0.58 \mathrm{~m} / \mathrm{s}$ ) was smaller than that of $1.7 \mathrm{~L} / \mathrm{min}$ (about $0.62 \mathrm{~m} / \mathrm{s}$ ). The maximum backward flow velocity at the bottom surface (about $1.25 \mathrm{~m} / \mathrm{s}$ ) was larger than that of $1.7 \mathrm{~L} / \mathrm{min}$ (about 1.15 $\mathrm{m} / \mathrm{s}$ ). Most of the energy was transported to the bottom surface, and little energy could be transported to the top surface, so the weld pool length was decreased at the top surface, but increased at the bottom surface. A teardropshaped top weld pool was easily formed. The molten metal flowed inward near the keyhole and at the middle of the top weld pool, resulting in the formation of the high-temperature zone at the centerline of the top weld pool, and the serious undercut formation.

\section{The Undercut Formation Mechanism}

Based on the above discussion, it can be concluded that the counterclockwise eddy inside the weld pool, and the backward and inward flow at the top surface of the weld pool have great influence on the undercut formation.

As shown in Fig. 14, the irregular fluid flow and uneven energy distribution mechanisms are proposed to be responsible for the undercut formation at the top surface. When the plasma gas rate is increased, the counterclockwise eddy inside the weld pool becomes stronger, and the backward flow at the top surface becomes weaker, so more energy is transported to the bottom surface, and less energy is transported to the top surface. The rear part of the top weld pool is easily solidified, so a teardrop-shaped profile is easily formed.

The teardrop-shaped weld pool profile contributes to the increase of the inward flow. It should be noted that when 


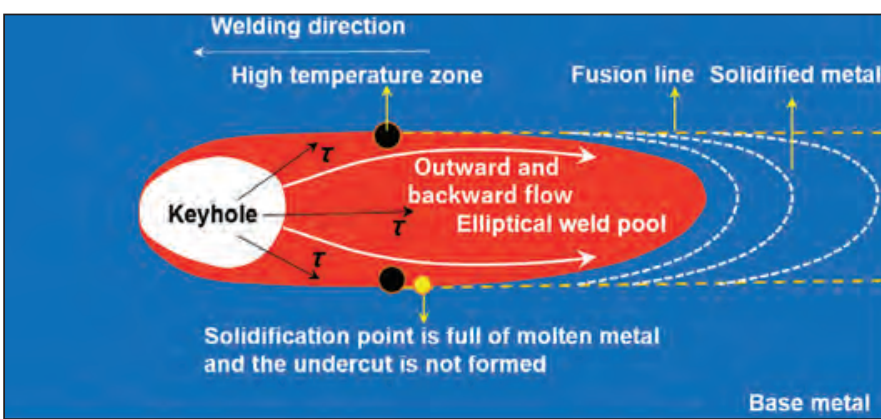

Fig. 12 - The dominant driven force of the weld pool convection when the plasma gas rate is $1.7 \mathrm{~L} / \mathrm{min}$.
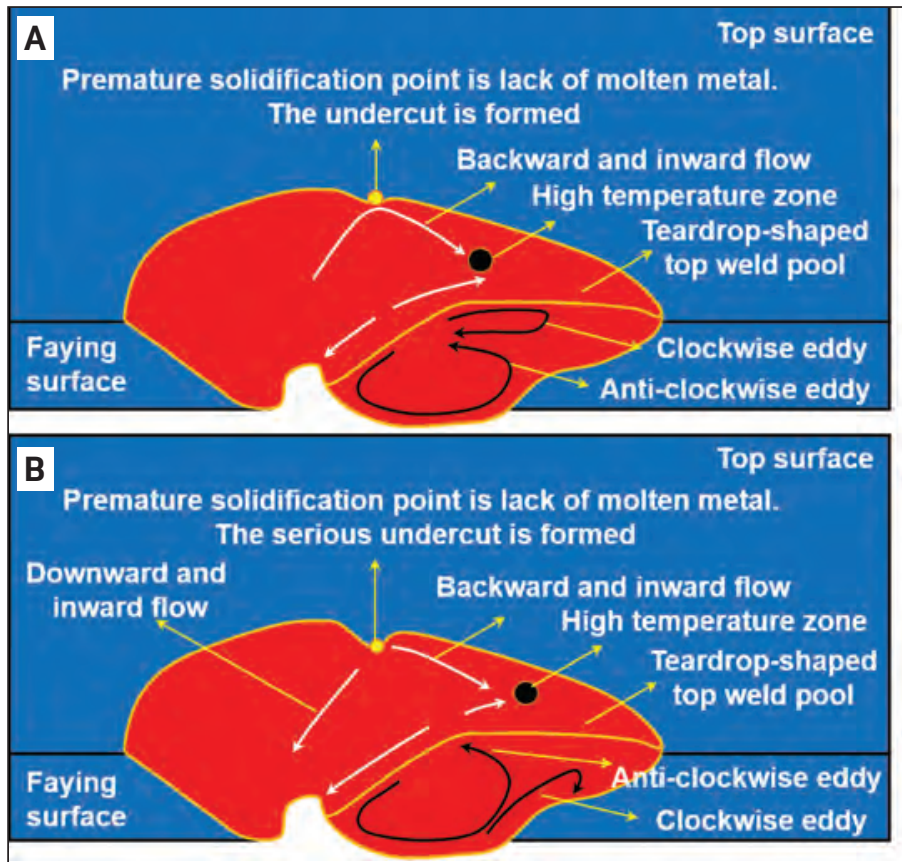

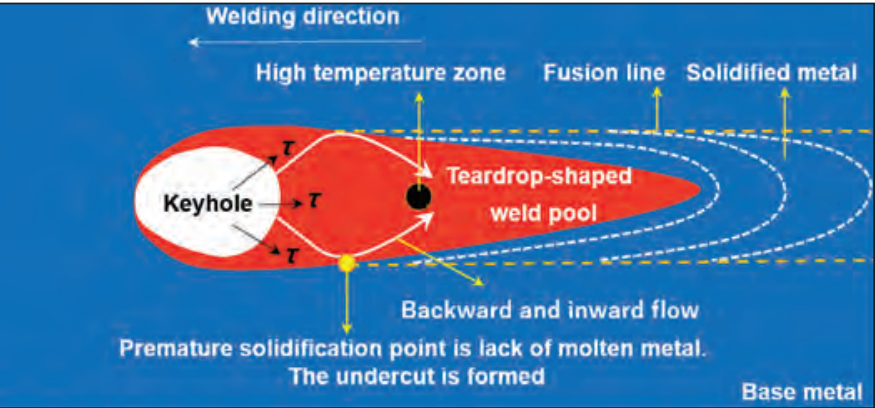

Fig. 13 - Schematic of the weld pool at the top view in the case of $1.7 \mathrm{~L} / \mathrm{min}$.
C

The irregular fluid flow

The anti-clockwise eddy

is increased, and the The inward flow at the backward flow at the top top surface is increased. surface is decreased.

\section{The uneven energy distribution}

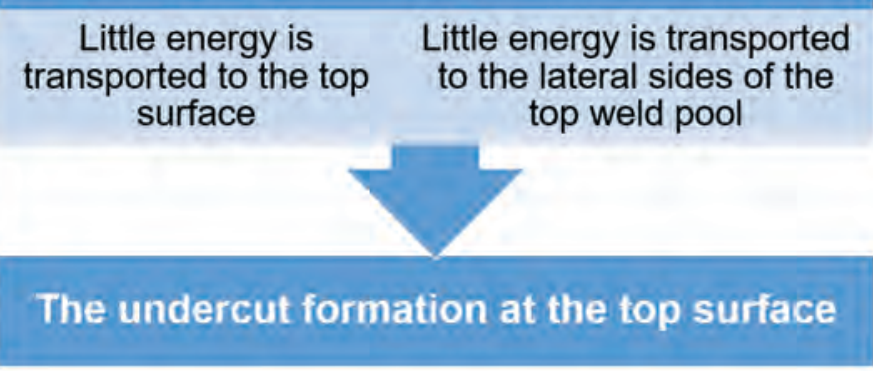

Fig. $14-A-$ Schematic of the undercut formation in the case of $1.7 \mathrm{~L} / \mathrm{min}$; B - schematic of the undercut formation in the case of $3 \mathrm{~L} / \mathrm{min} ; \mathrm{C}-$ the undercut formation mechanism.

the counterclockwise eddy inside the weld pool becomes dominant, as shown in Fig. 14B, the downward and inward flow can also be seen at the top surface near the rear keyhole wall. More molten metal and energy are transported from the lateral sides to the centerline of the top weld pool. The high-temperature zone is formed at the centerline of the top weld pool, and the lateral sides of the top weld pool are easily prematurely solidified, causing the undercut formation at the top surface.

It should be noted that more molten metal and energy are transported to the bottom surface, and inward flow can't be seen at the bottom surface, so the undercut is difficult to form at the bottom surface.

\section{Conclusions}

The following conclusions can be obtained:

In the blind keyhole case, due to the reverse flow of the arc plasma, the molten metal at the top surface flows outward and backward, and only a clockwise eddy is formed in- side the weld pool. The temperature of the molten metal at the lateral sides of the weld pool is high, and the undercut is not formed. The plasma shear stress is the dominant driven force for the weld pool convection, while the arc pressure has minor influence on it.

As the plasma gas rate is increased, a penetrated keyhole is formed. The counterclockwise eddy inside the weld pool becomes large, and then dominant. The backward flow at the top surface is decreased, while the inward flow caused by the teardrop-shaped top weld pool profile and the dominant counterclockwise eddy inside the weld pool is increased. The temperature of the molten metal at the lateral sides of the top weld pool is low.

In the KPAW process, the heat transportation by the fluid flow is the dominant mechanism for the energy transportation inside the weld pool. The strong counterclockwise eddy inside the weld pool, and the weak backward flow at the top surface, lead to the uneven energy distribution between the top and bottom surfaces. The strong inward flow causes the uneven energy distribution between the lateral 
sides and centerline of the top weld pool. All of these reasons contribute to the undercut formation at the top surface.

\section{Acknowledgments}

Dr. Nguyen and Dr. Wu contributed equally to this work, so they should be regarded as first joint authors.

\section{References}

1. Vilkas, E. P. 1991. Plasma arc welding of exhaust pipe system components. Welding Journal 70(4): 49-52.

2. Irving, B. 1997. Why aren't airplanes welded? Welding Journal 76(1): 34-41.

3. Irving, B. 1992. Plasma arc welding takes on the advanced solid rocket motor. Welding Journal 71(12): 49-52.

4. Martikainen, J. K., and Moisio, T. J. I. 1993. Investigation of the effect of welding parameters on weld quality of plasma arc keyhole welding of structural steels. Welding Journal 72(7): 329-s to 340-s.

5. Liu, Z. M., Wu, C. S., Liu, Y. K., and Luo, Z. 2015. Keyhole behaviors influence weld defects in plasma arc welding process. Welding Journal 94(9): 281-s to 290-s.

6. Mills, K. C., and Keene, B. J. 1990. Factors affecting variable weld penetration. International Materials Reviews 35(1): 185-216. DOI: $10.1179 / 095066090790323966$

7. Mendez, P. F., and Eagar, T. W. 2003. Penetration and defect formation in high-current arc welding. Welding Journal 82(10): 296-s to 306-s.

8. Meng, X., Qin, G., Bai, X., and Zou, Z. 2016. Numerical analysis of undercut defect mechanism in high speed gas tungsten arc welding. Journal of Materials Processing Technology 236: 225-234. DOI: 10.1016/j.jmatprotec.2016.05.020

9. Meng, X., Qin, G., and Zou, Z. 2017. Sensitivity of driving forces on molten pool behavior and defect formation in highspeed gas tungsten arc welding. International Journal of Heat and Mass Transfer 107: 1119-1128. DOI: 10.1016/j.ijheatmasstransfer.2016.11.025

10. Nishi, T., Fujita, H., Haseba, S., and Ohara, M. 1982. Study on high speed submerged arc welding (Report 1). Japan Welding Society 30(8): 68-74. DOI: 10.2207/qjjws1943.51.686

11. Ohara, M., Fujita, H., Haseba, S., and Nishi, T. 1983. Study on high speed submerged arc welding (Report 2). Japan Welding Society 31(2): 45-48. DOI: 10.2207/qjjws.1.133

12. Nguyen, T. C., Weckman, D. C., and Johnson, D. A. 2007. Predicting onset of high speed gas metal arc weld bead defects using dimensional analysis techniques. Science and Technology of Welding and Joining 12(7): 634-648. DOI: 10.1179/174329307X236797

13. Zong, R., Chen, J., Wu, C. S., and Padhy, G. K. 2017. Influence of molten metal flow on undercutting formation in GMAW. Science and Technology of Welding and Joining 22(3): 198-207. DOI: 10.1080/13621718.2016.1214406

14. Zong, R., Chen, J., Wu, C. S., and Chen, M. A. 2016. Undercutting formation mechanism in gas metal arc welding. Welding Journal 95(5): 174-s to 184-s.

15. Powell, J., Ilar, T., Frostevarg, J., Torkamany, M. J., Na, S J., Petring, D., and Kaplan, A. F. 2015. Weld root instabilities in fiber laser welding. Journal of Laser Applications 27(S2): S29008. DOI: $10.2351 / 1.4906390$

16. Zhang, M., Zhang, Z., Tang, K., Mao, C., Hu, Y., and Chen, G. 2018. Analysis of mechanisms of underfill in full penetration laser welding of thick stainless steel with a $10 \mathrm{~kW}$ fiber laser. Optics \& Laser Technology 98: 97-105. DOI: 10.1016/j.optlastec.2017.07.037

17. Liu, Z. M., Wu, C. S., and Chen, J. 2013. Sensing dynamic keyhole behaviors in controlled-pulse keyholing plasma arc welding. Welding Journal 92(12): 381-s to 389-s.

18. Wu, C. S., and Liu, Z. M. 2015. Dynamic variation of keyhole exit and its inclination in plasma arc welding. Welding in the World 59(3): 365-371. DOI: 10.1007/s40194-014-0206-z

19. Liu, Z., Wu, C., Cui, S., and Luo, Z. 2017. Correlation of keyhole exit deviation distance and weld pool thermo-state in plasma arc welding process. International Journal of Heat and Mass Transfer 104: 310-317. DOI: 10.1016/j.ijheatmasstransfer.2016.08.069

20. Li, T. Q., and Wu, C. S. 2015. Numerical simulation of plasma arc welding with keyhole-dependent heat source and arc pressure distribution. The International Journal of Advanced Manufacturing Technology 78(1-4): 593-602. DOI: 10.1007/s00170-0146685-7

21. Jian, X., Wu, C., Zhang, G., and Chen, J. 2015. A unified 3D model for an interaction mechanism of the plasma arc, weld pool and keyhole in plasma arc welding. Journal of Physics D: Applied Physics 48(46): 465504. DOI: 10.1088/0022-3727/48/46/465504

22. Li, Y., Feng, Y., Zhang, X., and Wu, C. 2014. Energy propagation in plasma arc welding with keyhole tracking. Energy 64: 1044-1056. DOI: 10.1016/j.energy.2013.11.018

23. Van, A. N., Tashiro, S., Van, H. B., and Tanaka, M. 2017. Experimental investigation on the weld pool formation process in plasma keyhole arc welding. Journal of Physics D: Applied Physics 51(1): 015204. DOI: 10.1088/1361-6463/aa9902

24. Yamazaki, K., Yamamoto, E., Suzuki, K., Koshiishi, F., Tashiro, S., Tanaka, M., and Nakata, K. 2013. Measurement of surface temperature of weld pools by infrared two colour pyrometry. Science and Technology of Welding and Joining 15(1): 40-47. DOI: 10.1179/136217109X12537145658814

25. Tashiro, S., Miyata, M., Tanaka, M., Shin, K., and Takahashi, K. 2010. Numerical analysis of keyhole welding of mild steel plate with the plasma arc. Transactions of JWRI 39(1): 27-31.

26. Kawahito, Y., Uemura, Y., Doi, Y., Mizutani, M., Nishimoto, K., Kawakami, H., and Katayama, S. 2017. Elucidation of the effect of welding speed on melt flows in high-brightness and high-power laser welding of stainless steel on basis of threedimensional x-ray transmission in situ observation. Welding International 31(3): 206-213. DOI: 10.1080/09507116.2016.1223204

27. Xu, B., Jiang, F., Chen, S., Tanaka, M., Tashiro, S., and Van, A. N. 2018. Numerical analysis of plasma arc physical characteristics under additional constraint of keyhole. Chinese Physics $B$ 27(3): 034701. DOI: 10.1088/1674-1056/27/3/034701

ANH VAN NGUYEN, DONGSHENG WU (d.wu@jwri.osaka-u.ac.jp), SHINICHI TASHIRO (tashiro@jwri.osaka-u.ac.jp), and MANABU TANAKA are with the Joining and Welding Research Institute, Osaka University, Ibaraki, Osaka, Japan. NGUYEN is also with Murata Welding Laboratories Ltd., Osaka, Yodogawaku, Japan, and WU is also with Shanghai Key Laboratory of Material Laser Processing and Modification (Shanghai Jiao Tong University), Shanghai, China. 